\title{
A Validity Study of the MweP Scale in Hong Kong
}

\author{
TSUN-LOK KWONG \\ University of Management and Technology, United States \\ kwonge@alumni.cuhk.net \\ PIK-CHING WAN \\ Teesside University, United Kingdom \\ wanpansy@outlook.com
}

This article examines the validity of the Multidimensional Work Ethic Profile, MWEP, in the Hong Kong setting. Purposive quota sampling is adopted to solicit data from a total of 140 respondents with equal gender distribution across seven age groups in Hong Kong. Factor analysis reveals that similarity exists between factor loadings in original MWEP model of Miller, Woehr, and Hudspeth (2002) and the model in the current study with Hong Kong samples. However, the MWEP items in the current study does not map exactly into the seven dimensions proposed by Miller, Woehr, and Hudspeth. The leisure and the morality/ethics dimensions match with the original scale respectively with good and poor reliabilities, but the hard work and wasted time dimensions have intertwined and appeared to be inseparable.

Key words: MWEP, work ethic, multidimensional, Hong Kong, validity

https://doi.org/10.26493/1854-4231.12.217-234

\section{Introduction}

Organizations nowadays place great concerns on the work ethic of their potential employees (Flynn 1994). Work ethic is a construct of moral belief that stresses the importance of working hard and the commitment of appropriate work-related values and attitudes (Li and Madsen 2009; Miller, Woehr, and Hudspeth 2002). Employees possessing strong work ethic would demonstrate good values not only through hard work but also autonomy, fairness, wisdom, time management, refrainment from immediate gratification and an appreciation of the intrinsic value of work (Cherrington 1980; Dubin 1963; Furnham 1984; Ho and Lloyd 1984; Weber 1958; Wollack et al. 1971). In contrast, the dwindling of work ethic would lead to decreased organizational commitment (Brief and Aldag 1980; Chusmir and Koberg 1988; Morrow and Goetz 1988; Morrow and McElory 
1987; Randall and Cote 1991), lower job involvement (Bass and Barrett 1972; Ho et al. 2012; Lodahl and Kejner 1965), reduced job satisfaction (Abboushi 1990; Aldag and Brief 1975; Ali 1987; Blood 1969; Bokemeir and Lacy 1987; Cherrington 1980; Chusmir and Koberg 1988; Fisher and Gitelson 1983; Jones 1984; Stone 1975; Meglino, Ravlin, and Adkins 1989; Morrow and McElory 1987; Saks, $\mathrm{Mu}-$ drack, and Ashforth 1996), poorer job performance (Yandle 1992), and higher levels of absenteeism and turnover (Klebnikov 1993; Shimko 1992). A proper measurement tool for work ethic is necessary if organizations would like to assess the ethical levels of their employees. The MWEP scale, designed in the West to measure work ethic, has been tested in many places but Hong Kong. Therefore, the suitability of the MWEP scale for measurement in Hong Kong has become an interesting topic for exploration in this study.

\section{Work Ethic}

Work ethic describes the set of beliefs, values, and attitudes that an individual assumes during work (Meriac, Woehr, and Banister 2010). It is a reflection of how an individual dedicates and commits to his/her work, and how he/she willingly exercises effort over and above the threshold requirements and expectations of the job (Kwong 2016; McMurray and Scott 2013). The 'work ethic' term was originally devised by post-reformation scholars who promoted individualism among society and discredited the welfare state (Miller, Woehr, and Hudspeth 2002). The scholars believed that individuals should be liable for their own well-beings in life and it is through hard work that any one individual could better his or her standard of living.

As the concept developed, the interpretation of 'work ethic' gradually evolved into a more concrete construct - the 'Protestant Ethic' of Max Weber (1958). The Protestant Ethic considered the ability to work and secure returns as fulfilling God's will and the labour desired by God (McMurray and Scott 2013; Weber 1958). The ethic of work resembled a kind of calling from the above and that individuals should work systematically and continuously to maximize the benefits of their labour and thus to glorify the name of God (Kwong 2016; Miller, Woehr, and Hudspeth 2002). Weber's construct therefore theorized on the basis of religious faith and duty, and it stressed personal beliefs and principles in the dimensions on centrality of work, self-reliance, hard work, leisure avoidance, morality, delay of gratification, and time utilization.

Today, the work ethic concept does not confine itself to any single 
culture or religion (Geren 2011). Occupational work ethic stretches across wide range of aspects and is a broad compilation of personal, family, religious, and ethnic beliefs and values (Petty and Hill 2005). According to Anca (2012), work ethic nowadays focuses on the essence of 'skills, discipline, challenge, autonomy, quality of work produced,' and positive work ethic aims at increasing employees' productivity through the achievement of optimal efficiency, mentality and status. The work ethic concept is a secular theory applicable to all religions and nations (Furnham 1990a; Miller, Woehr, and Hudspeth 2002).

\section{Measuring Work Ethic}

According to Miller, Woehr, and Hudspeth (2002), there are at least seven measurement instruments specifically designed to evaluate work ethic. These include the Protestant Ethic scale (Goldstein and Eichorn 1961), Pro-Protestant Ethic and non-Protestant Ethic scale (Blood 1969), Spirit of Capitalism (Hammond and Williams 1976), Protestant Work Ethic scale (Mirels and Garrett 1971), Work and Leisure Ethic scales (Bucholz 1978), Eclectic Protestant Ethic scale (Ray 1982), and the Australian Work Ethic scale (Ho and Lloyd 1984). The measurement of work ethic varies greatly among previous researches because work ethic can be measured as a multidimensional construct as well as a single-dimensional construct. Among these seven named instruments, the Protestant Work Ethic $(\mathrm{PWE})$ scale is the more commonly used work ethic measurement tool that has been applied in many work ethic studies and researches in the past (Dunn 2013; Miller, Woehr, and Hudspeth 2002).

Furnham (199ob) conducted a factor analysis based on the seven aforementioned work ethic questionnaires and identified five interpretable factors: asceticism, belief in hard work, leisure, religious and moral beliefs and independences. Tang (1993), basing on the PWE scale, developed four factors - hard work, internal motive, asceticism and attitude toward leisure - with a Taiwanese sample. Using again the PWE scale, Mchoskey (1994) conducted a factor analysis and identified four factors: success, asceticism, hard work and anti-leisure. However, though the factors identified in different researches mostly resembled one another, some important aspects such as an individual's attitudes toward morality, self-reliance, or delay of gratification were absent. These four-factor or five-factor scales are considered to be multidimensional, yet their effectiveness and application remained to be limited.

Although protestant work ethic has been developed into many 
scales, there is still a lack of common measurement system to measure the work ethic globally. Many believe that work ethic is not necessarily tied to any set of religious beliefs, and so, the development of a universal work ethic scale has become a popular topic for scholars.

\section{Multidimensional Work Ethic Profile}

Miller, Woehr, and Hudspeth (2002) criticized the different protestant work ethic scales for their inclination to the religious morals, and they proposed the adoption of a universal work ethic scale, Multidimensional Work Ethic Profile (MWEP). Miller, Woehr, and Hudspeth's exploratory factor analysis resulted in seven dimensions alike the original thesis of Weber (1958) and the interpretable factors of Furnham (1990b), namely belief in hard work, the role of leisure, waste time, religious and moral beliefs, self-reliance, asceticism and delay of gratification. The scale was later applied internationally in England, Spain, Korea, Iran, Turkey, Chinese Mainland, and South African.

The MWEP has been translated into different languages as it is applied in different countries. However, Woehr, Arciniega, and Lim (2007) challenged that Miller, Woehr, and Hudspeth (2002) did not provide enough evidence to prove the appropriateness of the MWEP as a universal measurement tool across cultures. To bring the MWEP to a cross-cultural setting, they investigated the measurement invariance and mean differences of work ethic dimensions with the same set of seven work ethic dimensions in English, Spanish and Korean versions. Results showed that the MWEP scales were equivalent across the three samples.

Chanzanagh and Akbarnejad (2011) measured the validity of MWEP in Iran's Islamic culture. Their research showed that the scale in Persian version have a close proximity to MWEP in both original English and newly developed Spanish and Korean versions (Woher, Arciniega, and Lim 2007) and work ethic dimensions in these cultures can also be applied to Persian version. However, Ozatalay and Chanzanagh (2013) developed and tested a MWEP in Turkish language and indicated that not all the work ethic dimensions proposed by Miller, Woehr, and Hudspeth (2002) can actually be measured by Turkish version of MWEP.

Slabbert and Ukpere (2011) developed the Mandarin and Xhosa versions to compare the work-ethic differences of the Chinese and South African workforces to study the difference in behaviour towards work between the two countries. A total of 315 workers participated the studies, 153 from two factories in China and 162 from 
three factories in South African. They found that Chinese samples scored higher than South African samples in all dimensions except leisure. South Africans concern more on having free time than the Chinese. Higher work ethic level might be one of the reasons why China, then an extremely poor country in the 1970s, can grow rapidly and become the third biggest national economy within a short period of time.

Based on review of literatures related to work ethic, work ethic scales, and the Multidimensional Work Ethic Profile around the world, this study positioned itself to investigate the application of the MWEP in Hong Kong setting and to test the validity of the MWEP against Miller, Woehr, and Hudspeth's original scale.

\section{Method}

SAMPLING

This study used purposive sampling technique to collect the necessary data from the different members of population. Heterogeneous quota sampling was adopted to select sample with diverse characteristics. Data of 10 male respondents and 10 female respondents across seven age groups - 17-22, 23-28, 29-33, 34-40, 41-45, 46-50, and over 50 - was collected. These age groups took reference from the Levinson's Stages of Adult Development (Dean 2007), which proposed that different stages of life mark important behavioural and psychological transitions of people. A total of 140 individuals had provided their response to this study. The mean age of the sample was 37.1 and the standard deviation was 11.9.

\section{INSTRUMENT}

The MWEP scale was distributed to the sample in the form of selfreport questionnaires. The scale contains 65 items measuring seven conceptually different dimensions of work ethic (Miller, Woehr, and Hudspeth 2002):

1. hard work (belief in the intrinsic value of hard work),

2. self-reliance (belief in independence from other people),

3. leisure (belief in the value of free time),

4. work centrality (belief in the importance of work in life),

5. morality/ethics (belief in righteousness),

6. delay of gratification and wasted time (willingness to postpone pleasure). 
TABLE 1 KMO and Bartlett's Test

\begin{tabular}{llr}
\hline Kaiser-Meyer-Olkin measure of sampling adequacy & 0.760 \\
\hline Bartlett's test of sphericity & Approx. chi-square & 5025.569 \\
& Degrees of freedom & 2080 \\
& Significance & 0.000 \\
\hline
\end{tabular}

Each of the seven dimensions was assessed with 10 items except 'the delay of gratification' and 'wasted time' dimensions which were assessed with 7 and 8 items respectively. All items are responded on a Likert scale between 1 and 5, where 1 representing 'strongly disagree' and 5 representing 'strongly agree.' The completion of questionnaire was fully voluntary, and no financial incentives were given to the respondents.

\section{Results}

VALIDITY OF THE MWEP SCALE

The primary objective of this paper is to test the validity of the MWEP against the Miller, Woehr, and Hudspeth's original scale. As summarized in table 1 , results of $\mathrm{KMO}=0.760$, greater than 0.5 as suggested by Tabachnick and Fidell (2007) and Hair et al. (2006), showed that the number of respondents is sufficient for factor analysis to be performed. Bartlett's Sphericity is 5025.569 with a significance level of $p=0.000$, and this reflected that each factor is correlated with each other at high root and the significant amount is accurately done.

Based on the favourable results from the кмо and Bartlett's test, the validity of the MWEP is tested with factor analysis using two different rotation methods.

\section{FACTOR ANALYSIS OF THE MWEP ITEMS USING VARIMAX ROTATION}

An initial factor analysis pre-setting 7 factors, principal components method and Varimax rotation is used to examine how the 65 items on the MWEP are loaded around the factors. Varimax rotation typically maximizes the variance of the squared loadings in each factor such that each factor only ends up with fewer variables with high loadings (Mulaik 2010). As summarized in table 2, the result of Scree's test showed that the 7 factors could explain up to 48.3 percent of the variance in observations.

Table 3 summarized the loading of the 65 MWEP items after factor analysis with Varimax rotation. Items in the middle column are factored according to Miller, Woehr, and Hudspeth's original MWEP

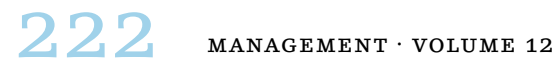


TABLE 2 Total Variance Explained (Principal Component, Varimax)

\begin{tabular}{|c|c|c|c|c|c|c|c|c|c|}
\hline \multirow[t]{2}{*}{ (1) } & \multicolumn{3}{|c|}{ Initial eigenvalues } & \multicolumn{3}{|c|}{$\begin{array}{c}\text { Extraction sums of } \\
\text { squared loadings }\end{array}$} & \multicolumn{3}{|c|}{$\begin{array}{l}\text { Rotation sums of } \\
\text { squared loadings }\end{array}$} \\
\hline & (2) & (3) & (4) & (2) & (3) & (4) & (2) & (3) & (4) \\
\hline 1 & 14.119 & 21.721 & 21.721 & 14.119 & 21.721 & 21.721 & 10.654 & 16.390 & 16.390 \\
\hline 2 & 5.499 & 8.460 & 30.181 & 5.499 & 8.460 & 30.181 & 5.288 & 8.136 & 24.526 \\
\hline 3 & $3 \cdot 379$ & 5.198 & $35 \cdot 379$ & $3 \cdot 379$ & 5.198 & $35 \cdot 379$ & 3.909 & 6.014 & 30.540 \\
\hline 4 & 2.276 & 3.501 & 38.880 & 2.276 & 3.501 & 38.880 & $3 \cdot 781$ & 5.817 & $36.35^{8}$ \\
\hline 5 & 2.130 & 3.277 & 42.157 & 2.130 & 3.277 & 42.157 & 3.149 & 4.844 & 41.202 \\
\hline 6 & 2.020 & 3.108 & 45.265 & 2.020 & 3.108 & 45.265 & 2.416 & 3.717 & 44.919 \\
\hline 7 & 1.968 & 3.027 & 48.292 & 1.968 & 3.027 & 48.292 & 2.192 & $3 \cdot 373$ & 48.292 \\
\hline
\end{tabular}

Nотеs Column headings are as follows: (1) component, (2) total, (3) percentage of variance, (4) cumulative percentage.

TABLE 3 Item's Loading after Factor Analysis (Principal Component, Varimax)

\begin{tabular}{|c|c|c|}
\hline Factor/Dimensions & $\begin{array}{l}\text { Miller, Woehr, and Hud- } \\
\text { speth (2002) }\end{array}$ & Current study (Varimax) \\
\hline Hard Work & $\begin{array}{l}17,20,22,24,35,38,45,47 \\
53,60\end{array}$ & $\begin{array}{l}45, \mathbf{3 6}, 20,24,22, \mathbf{9}, \mathbf{2 3}, 64 \\
\mathbf{1 2}, 21,47,44,56,4,38,13 \\
\mathbf{3 9}, 46,53,35,52,30, \mathbf{1}, 60 \\
59,6,17,50\end{array}$ \\
\hline Wasted Time & $1,9,12,23,36,39,56,65$ & \\
\hline Leisure & $\begin{array}{l}5,8,14,18,27,31,43,49,58, \\
63\end{array}$ & $14,58,31,43,8,5,49,18,63$ \\
\hline Morality/Ethics & $\begin{array}{l}7,15,16,25,37,48,51,54 \\
57,61\end{array}$ & $\begin{array}{l}57,61,16,48,29,51,54,37, \\
15,27\end{array}$ \\
\hline Self-Reliance & $\begin{array}{l}6,21,26,28,32,34,44,50 \\
55,59\end{array}$ & $34,32,55,28,26,33,65$ \\
\hline Centrality of Work & $\begin{array}{l}2,4,10,13,30,33,40,41,52 \\
64\end{array}$ & $40,10,41,2$ \\
\hline Delay of Gratification & $3,11,19,29,42,46,62$ & $11,25,7,3,19$ \\
\hline $\mathrm{N} / \mathrm{A}$ & & 62,42 \\
\hline
\end{tabular}

scale. Items in the right column are results of the current study and are arranged in a descending order of their factor loadings, where items with greater loadings will appear before those with smaller loadings.

The way the items are loaded proved that there are some similarities between Miller, Woehr, and Hudspeth's study and the current study in a Hong Kong setting. The items italicised in table 3 are the matching items between Miller, Woehr, and Hudspeth's study and the current study with Hong Kong respondents. 9 out of 10 items in the leisure dimension, 8 out of 10 items in the morality/ethics dimen- 
TABLE 4 Total Variance Explained (Principal Component, Equamax)

\begin{tabular}{|c|c|c|c|c|c|c|c|c|c|}
\hline \multirow[t]{2}{*}{ (1) } & \multicolumn{3}{|c|}{ Initial eigenvalues } & \multicolumn{3}{|c|}{$\begin{array}{l}\text { Extraction sums of } \\
\text { squared loadings }\end{array}$} & \multicolumn{3}{|c|}{$\begin{array}{l}\text { Rotation sums of } \\
\text { squared loadings }\end{array}$} \\
\hline & $(2)$ & (3) & (4) & $(2)$ & (3) & (4) & $(2)$ & (3) & (4) \\
\hline 1 & 14.119 & 21.721 & 21.721 & 14.119 & 21.721 & 21.721 & 5.356 & 8.240 & 8.240 \\
\hline 2 & 5 & 8.460 & 30. & 9 & 8.460 & 30 & 85 & 7.977 & 16.217 \\
\hline 3 & 3.379 & 5.198 & $35 \cdot 379$ & 3.379 & 5.198 & $35 \cdot 379$ & $4 \cdot 397$ & 6.765 & 22.982 \\
\hline 4 & 2.276 & 3.501 & 38.880 & 2.276 & 3.501 & 38.880 & 4.304 & 6.621 & 29.603 \\
\hline 5 & 2.130 & 3.277 & 42.157 & 2.130 & 3.277 & 42.157 & 4.286 & 6.594 & 36.198 \\
\hline 6 & 2.020 & 3.108 & 45.265 & 2.020 & 3.108 & 45.265 & 4.282 & 6.588 & 42.786 \\
\hline 7 & 1.968 & 3.027 & 48.292 & 1.968 & 3.027 & 48.292 & 3.579 & 5.506 & 48.292 \\
\hline
\end{tabular}

Notes Column headings are as follows: (1) component, (2) total, (3) percentage of variance, (4) cumulative percentage.

sion, 5 out of 10 items in the self-reliance dimension, and 4 out of 10 items in the centrality of work dimension in Miller, Woehr, and Hudspeth's original model concur with the corresponding dimensions in this current study.

Careful cross examination of the dimensions reveals some interesting findings. The items in bold reflect the unexpected but similar distribution of the MWEP items between the original model and the current model that are diagonally loaded into adjacent dimensions. All the 10 items in the hard work dimension, 7 out of 8 items in wasted time dimension, and some of the items in the centrality of work and self-reliance dimensions in Miller, Woehr, and Hudspeth's original model have been merged into one single dimension with 28 items in the current study. The delay of gratification dimension in the original model has also been statistically separated into two dimensions in this study.

\section{FACTOR ANALYSIS OF THE MWEP ITEMS \\ USING EQUAMAX ROTATION}

The Varimax rotation used in the initial factor analysis has resulted in large percentage of variance distributed in the first factor. A subsequent factor analysis pre-setting 7 factors, principal components method and Equamax rotation - a different orthogonal rotation approach - is used to examine how differently the 65 MWEP items are loaded. Equamax rotation attempts to adjust the number of rotated factors with highly loaded and more uniformly distributed sets of variables (Mulaik 2010). As summarized in table 4, the result of Scree's test showed that the variables are now rotated and distributed more uniformly among the 7 factors. 
TABLE 5 Item's Loading after Factor Analysis (Principal Component, Equamax)

\begin{tabular}{|c|c|c|}
\hline Factor/Dimensions & $\begin{array}{l}\text { Miller, Woehr, and Hud- } \\
\text { speth (2002) }\end{array}$ & Current study (Equamax) \\
\hline Wasted Time & $1,9,12,23,36,39,56,65$ & $\begin{array}{l}12,36,47,23,44,56,39,51 \\
64,50,52,30\end{array}$ \\
\hline Leisure & $\begin{array}{l}5,8,14,18,27,31,43,49,58, \\
63\end{array}$ & $\begin{array}{l}14,58,31,43,8,5,49,18,63, \\
27\end{array}$ \\
\hline Delay of Gratification & $3,11,19,29,42,46,62$ & $\begin{array}{l}46,29,19,11,24,38,41,40 \\
21,35\end{array}$ \\
\hline Morality/Ethics & $\begin{array}{l}7,15,16,25,37,48,51,54, \\
57,61\end{array}$ & $16,7,48,25,54,57,15,3,37$ \\
\hline Centrality of Work & $\begin{array}{l}2,4,10,13,30,33,40,41,52, \\
64\end{array}$ & $13,4,9,2,45,20,22,1,10$ \\
\hline Self-reliance & $\begin{array}{l}6,21,26,28,32,34,44,50 \\
55,59,\end{array}$ & $34,32,28,26,55,59,6,33$ \\
\hline Hard Work & $\begin{array}{l}17,20,22,24,35,38,45,47, \\
53,60\end{array}$ & $62,60,61,53,65,42,17$ \\
\hline
\end{tabular}

Table 5 summarized the loading of the 65 MWEP items after factor analysis with Equamax rotation. Items on the middle column are again factored according to Miller, Woehr, and Hudspeth's original MWEP scale. Items on the right column are results of the current study and are arranged in a descending order of their factor loadings, with items having greater loadings appearing before those with smaller loadings.

An examination of the variables loading in the seven dimensions again shows similarities between Miller, Woehr, and Hudspeth's (2002) study and the current Hong Kong study when data are rotated with Equamax method. All the 10 items in the leisure dimension in the current study map exactly to the Miller, Woehr, and Hudspeth's study (2002). 8 out of 10 items in the morality/ethics dimension and 7 out of 10 items in the self-reliance dimension in Miller, Woehr, and Hudspeth's original model concur with the two corresponding dimensions in this current study. For the remaining four dimensions, the items in the current study are partially mapped to the corresponding dimensions in Miller, Woehr, and Hudspeth's original model.

\section{RELIABILITY OF THE MWEP SCALE}

Based on the way the MWEP items are loaded with factor analyses using Varimax and Equamax rotation, the Cronbach's coefficient alphas are calculated to examine the reliability of the dimensions, and the reliability estimates for each dimension are summarized in table 
table 6 Reliability Estimates for Each Dimension by Sample (Principal Component, Varimax)

\begin{tabular}{lrr}
\hline Factor/Dimensions & Items number & Reliability \\
\hline Leisure & 9 & 0.852 \\
Self-Reliance & 7 & 0.733 \\
Hard Work/Wasted Time & 28 & 0.932 \\
Centrality of Work & 4 & 0.479 \\
Delay of Gratification (I) & 5 & 0.615 \\
Delay of Gratification (II) & 2 & 0.343 \\
Morality/Ethics & 10 & 0.285 \\
\hline MWEP & 65 & 0.917 \\
\hline
\end{tabular}

TABLE 7 Reliability Estimates for Each Dimension by Sample (Principal Component, Equamax)

\begin{tabular}{lrr}
\hline Factor/Dimensions & Items number & Reliability \\
\hline Leisure & 10 & 0.845 \\
Self-Reliance & 8 & 0.781 \\
Hard Work & 7 & 0.584 \\
Wasted Time & 12 & 0.879 \\
Centrality of Work & 9 & 0.767 \\
Delay of Gratification & 10 & 0.797 \\
Morality/Ethics & 9 & 0.254 \\
\hline MWEP & 65 & 0.917 \\
\hline
\end{tabular}

6 and 7. The reliability results indicate that the MWEP is overall reliable with Cronbach's coefficient alpha of 0.917. The 'leisure' (0.852 in Varimax; 0.845 in Equamax) and 'self-reliance' (o.733 in Varimax; 0.781 in Equamax) dimensions are consistently reliable regardless of the rotation method adopted in the factor analysis. The 'morality/ethics' (0.285 in Varimax; 0.254 in Equamax dimension is, on the other hand, consistently showing low reliability under both rotation methods.

\section{Discussion}

Miller, Woehr, and Hudspeth (2002) have contributed to the field of work ethic research through the introduction of the Multidimensional Work Ethic Profile (MWEP), which attempts to become a contemporary, universally applicable scale for the measurement of work ethic across different religions and culture. The MWEP has been developed with the foundations of Weber's concept of work ethic, and has managed to devise seven theoretically isolatable dimensions within the work ethic construct. As Miller, Woehr, and Hudspeth 
TABLE 8 Matched Items in the Leisure Dimension and the Reliability Tests of All Loaded Items in the Leisure Dimension by Studies

\begin{tabular}{lrr}
\hline Studies & $\begin{array}{r}\text { Matched items } \\
\text { number }\end{array}$ & $\begin{array}{r}\text { Reliability of all } \\
\text { loaded items }\end{array}$ \\
\hline Chanzanagh and Akbarnejad 2011 & 8 & 0.799 \\
Ozatalay and Chanzanagh 2013 & 9 & 0.788 \\
Current study (Varimax rotation) & 9 & 0.852 \\
Current study (Equamax rotation) & 10 & 0.845 \\
\hline
\end{tabular}

(2002) aspired, the introduction of the MWEP should act as a springboard for future studies in work ethic and behaviours as well as the examination of the relationship between work ethic and behaviours.

Meanwhile, researchers around the world have been testing the validity of the MWEP, and also translating the MWEP into different languages to overcome the fundamental language barrier of the MWEP worded in English. The primary objective of the current study examines the validity of the MWEP in Hong Kong where the Western cultures collide with the Eastern cultures.

The findings in this study have shown similar differential relations among the seven factors as in Miller, Woehr, and Hudspeth's original framework. The leisure dimension matches more reliably with the factor loading in the original scale. The morality/ethics dimension observes many matched items, but has sustained the lowest reliability among all the dimensions. The hard work and wasted time dimensions have appeared to be intertwined and difficult to be isolated in our factor analysis.

\section{THE WELL-ESTABLISHED DIMENSION: LEISURE}

The leisure dimension is perhaps the least disputable dimension in the MWEP. Table 8 summarizes the findings relating to the leisure dimension in two previous studies in Turkish and Islamic settings and the findings in the current study. Comparing with two previous studies, the findings in the current study is consistent in showing the leisure dimension as a reliable and conceptually identifiable dimension in the whole work ethic construct. The number of items matching with Miller, Woehr, and Hudspeth's original framework rests at 8 or above out of 10 items. The reliability ranges from 0.788 to 0.852 which is also very high.

One possible reason for such observation could be because the leisure dimension is negatively correlated with the other dimensions in Miller, Woehr, and Hudspeth's model (2002). The leisure dimen- 
sion is therefore sufficiently different from the other dimensions in the scale, making it more readily distinguishable by the respondents and by the statistical analyses performed. Another reason could well be due to the wordings of the MWEP in which 8 out of 10 items of the leisure dimension include the word 'leisure' in the description, and the connotation of 'leisure' - which resembles a preference for nonwork activities - forms a huge contrast to the concept of work ethic or hard work. This results in an easy isolation of the leisure items, and thus the dimension, from the other dimensions.

THE UNRELIABLE DIMENSION: MORALITY/ETHICS

The morality/ethics dimension has a significantly lower reliability (below 0.3) than the other dimensions in the current study. This lower level of reliability is consistent regardless of the method of rotation adopted. Table 9 summarizes the findings relating to the morality/ethics dimension in two previous studies in Turkish and Islamic settings and the findings in the current study. Several inconsistencies are noted in the number of matched items and also in the level of reliability observed. For example, in Ozatalay and Chanzanagh's study (2013), only 4 out of 12 items were loaded to the morality/ethics dimension have matched with Miller, Woehr, and Hudspeth's original framework. The higher reliability observed simply reflects the internal consistency among the 4 matched items and the other 8 non-matched items.

The reliabilities of the morality/ethics dimension obtained in the current study are not only significantly lower than the reliabilities of other dimensions, they are also significantly lower than the reliabilities of the morality/ethics dimension in the previous studies in different countries. Therefore, some cultural factors may have played a role in the difference in the number of matched items and the reliabilities observed. In other words, there may be different interpretations of what constitutes a just and moral belief among people of different nationality and culture. As a result, the respondents have different levels of agreement or disagreement to the moral/ethical statements in the MWEP, and this leads to the variations in reliability estimates.

Indeed, a similar observation of lower reliability was noted in study 4 of Miller, Woehr, and Hudspeth's study (2002) with the Air Force sample. The rationalization then was that the items in the morality/ethics dimension are fairly clear-cut and transparent, and the respondents may not respond honestly given their association to the disciplined unit. This explanation may also be applicable in the 
TABLE 9 Matched Items in the Morality/Ethics Dimension and the Reliability Tests of All Loaded Items in the Morality/Ethics Dimension by Studies

\begin{tabular}{lrr}
\hline Studies & $\begin{array}{r}\text { Matched items } \\
\text { number }\end{array}$ & $\begin{array}{r}\text { Reliability of all } \\
\text { loaded items }\end{array}$ \\
\hline Chanzanagh and Akbarnejad 2011 & 10 & 0.636 \\
Ozatalay and Chanzanagh 2013 & 4 & 0.731 \\
Current study (Varimax rotation) & 10 & 0.285 \\
Current study (Equamax rotation) & 9 & 0.254 \\
\hline
\end{tabular}

current study where respondents come from a broad age group and different walks of life, and therefore they responded to the morality/ethics items differently owing to the different roles, experience, associations, and affiliations that they have. The mean score of the morality/ethics dimension (4.31 out of 5) in the current study also reflects that the respondents are likely to be compelled to socially desirable manners and have responded to the MWEP questionnaires in a less truthful manner.

THE INDIVISIBLE DIMENSIONS: HARD WORK AND WASTED TIME

In the current study, the hard work and wasted time dimensions have conjoined with one another in the factor analysis under Varimax rotation. As summarized in table 3, 10 items in the hard work dimension and 7 items in wasted time dimension, with other discrete items in Miller, Woehr, and Hudspeth's original model have merged into a single dimension with 28 items in the current study.

Cultural factors again could have played a part in this convergence of dimensions, but a more probable explanation is that, in the Hong Kong people's perception, to work hard is much similar to using their time actively and productively. People in Hong Kong work for long hours, nearly 50 hours per week -10 hours per day in a 5-day work week (Kwong 2016), are subconsciously conditioned to associate long and non-wasteful use of working hours with hard work. When workers work for long hours and avoid time wastage throughout their work, they believe they have work hard, whether or not the work will lead to success or achievement of goals. This understanding could be quite different from the original definitions in Miller, Woehr, and Hudspeth's model. Therefore, the items in the two dimensions may have appeared to be fairly indivisible to the Hong Kong respondents.

In the current study, since the Varimax rotation has resulted in a heavily loaded single factor, the Equamax rotation has been used to perform a subsequent factor analysis to spread the items more 
evenly across the seven dimensions. It is thus with the aid of the Equamax rotation method that the hard work and wasted time dimensions are finally separated.

However, one must be cautioned that the divisible seven dimensions are merely the result of the Equamax rotation which has adjusted, or 'shuffled,' the variable items more uniformly across the specified number of dimensions. In reality, the respondents in Hong Kong still perceive the hard work and wasted time dimensions in a fairly indistinguishable manner.

\section{Limitations and Future Research}

There are several limitations to be recognized in the current research. First, this study utilizes the purposive sampling technique which is a non-probability sampling approach. The information collected is therefore subjected to generalizability and external validity challenges (Saunders et al. 2009). Readers should be careful when trying to generalize the findings of this research to the whole Hong Kong population. Despite so, the researchers have placed substantial effort in ensuring that heterogeneous groups of respondents are adopted to maximize the variations in the sample. Second, the small sample size of 140 is fairly small compared to the population of over 7 million in Hong Kong. This again raises concerns on the external validity of the reported findings. Thirdly, the use of questionnaire as a method of data collection may constitute to biasness. For any selfreport study, the participants may exaggerate or under-report certain responses in the questionnaires due to various biasness such as positive skew, central tendency, social desirability, primacy and recency, and others. This may create another construct validity concern.

Finally, the use of questionnaire surveyed at a particular point of time has limited the information collected to a specific static instance of time. Information collected may differ at a different instance but there is no way to account for those differences when only static field study is conducted.

Future research can attempt to use a larger sample with stratified random sampling, which is a type of probability sampling. This can provide more accurate and solid verifications to the findings in the current study, and strengthen the generalizability of the results. Additionally, linguistics research can also be conducted to revisit the choice of words and expressions in the MWEP items to enhance the validity and reliability of the scale for measurement of the 7 dimensions of work ethic.

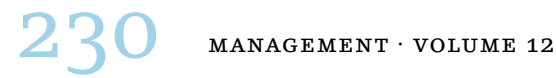




\section{References}

Abboushi, S. 1990. 'Impact of Individual Variables on the Work Values of Palestinian Arabs.' International Studies of Management \& Organization 20 (3): 53-68.

Aldag, R. J., and A. P. Brief. 1975. 'Some Correlates of Work Values.' Journal of Applied Psychology 60:757-60.

Ali, A. J. 1987. 'Values System as Predictor of Work Satisfaction of Arab Executives.' International Journal of Manpower 18 (2): 3-6.

Anca, P. 2012. 'Work Ethics in Romanian Companies (I): Empirical Evidences.' Annals of the University of Oradea, Economic Science Series 21 (1): 568-74.

Bass, B. M., and G. V. Barrett. 1972. Man, Work, and Organizations. Boston, ma: Allyn Brown.

Blood, M. R. 1969. 'Work Values and Job Satisfaction.' Journal of Applied Psychology 53 (6): 456-9.

Bokemeir, J. L., and W. B. Lacy. 1987. 'Job Values, Rewards and Work Conditions as Factors in Job Satisfaction among Men and Women.' Sociological Quarterly 28:189-204.

Brief, A. P., and R. J. Aldag. 1980. 'Antecedents of Organizational Commitment among Hospital Nurses.' Sociology of Work and Occupations 7:210-21.

Buchholz, R. 1978. 'An Empirical Study of Contemporary Beliefs about Work in American Society.' Journal of Applied Psychology 63:219-27.

Chanzanagh, H. E., and M. Akbarnejad. 2011. 'Examining MWEP and Its Validity in an Islamic Society: A National Study in Iran.' Procedia: Social and Behavioural Sciences 30:1430-7.

Cherrington, D. J. 1980. The Work Ethic: Working Values and Values That Work. New York: Aмасом.

Chusmir, L. H., and C. C. Koberg. 1988. 'Religion and Attitudes toward Work: A New Look at an Old Question.' Journal of Organizational Behaviour 9 (3): 251-62.

Dean, G. J. 2007. An Introduction to Adult Development: Fieldnotes for ABLE Staff. Lancaster-Lebanon, PA: Department of Education.

Dubin, R. 1963. Industrial Worker's Worlds: A Study of the 'Central Life Interests' of Industrial Workers. New Haven, с т: College and University Press.

Dunn, A. 2013. 'Only Fools? Reconsidering the Relationship between Commitment to the Work Ethic and Educational Attainment.' Journal of Education and Work 26 (1): 1-20.

Fisher, C. D., and R. Gitelson. 1983. 'A Meta-Analysis of the Correlates of Role Conflict and Ambiguity.' Journal of Applied Psychology 68:32033.

Flynn, G. 1994. 'Attitude More Valued Than Ability.' Personnel Journal 73 (9): 16. 
Furnham, A. 1984. 'The Protestant Work Ethic: A Review of the Psychological Literature.' European Journal of Social Psychology 14:87-104.

- 1990a. The Protestant Work Ethic: The Psychology of WorkRelated Beliefs and Behaviours. London: Routledge.

- 199ob. 'A Content, Correlational, and Factor Analytic Study of Seven Questionnaire Measures of the Protestant Work Ethic.' $\mathrm{Hu}$ man Relations 43:383-99.

Geren, B. 2011. 'The Work Ethic: Is It Universal?' Journal of International Business and Cultural Studies 5:1-9.

Goldstein, B., and R. Eichhorn. 1961. 'The Changing Protestant Ethic: Rural Patterns in Health, Work and Leisure.' American Sociological Review 26:557-65.

Hammond, P., and R. Williams. 1976. 'The Protestant Ethic Thesis: A Social Psychological Assessment.' Social Forces 54:579-89.

Hair, J. F., W. C. Black, B. J. Babin, R. E. Anderson, and R. L. Tatham. 2006. Multivariate Data Analysis. 6th ed. Upper Saddle River, NY: Pearson.

Ho, R., and J. I. Lloyd. 1984. 'Development of an Australian Work Ethic Scale.' Australian Psychologist 19:21-332.

Ho, C. C., B. Oldenburg, G. Day, and J. Sun. 2012. 'Work Values, Job Involvement, and Organizational Commitment in Taiwanese Nurses.' International Journal of Psychology and Behavioral Sciences 2 (3): 6470.

Jones. A. P. 1984. 'Organizational Reward Systems: Implications for Climate.' Motivation and Emotion 8:259-74.

Klebnikov, P. 1993. 'The Swedish Disease.' Forbes, 24 May.

Kwong, T. L. 2016. 'How Does Millennials' Perception on Their Employers Affect Their Work Ethic? A Study in Hong Kong.' Management 11 (4): 289-308.

Li, J., and J. Madsen. 2009. 'Chinese Workers Work Ethic in Reformed State-Owned Enterprises: Implications for HRD.' Human Resource Development International 12 (2): 171-87.

Lodahl, T. M., and M. Kejner. 1965. 'The Definition and Measurement of Job Involvement.' Journal of Applied Psychology 49:24-33.

McHoskey, J. W. 1994. 'Factor Structure of the Protestant Work Ethic Scale.' Personality and Individual Differences 17:49-52.

McMurray, A., and D. Scott. 2013. 'Work Values Ethic, GNP Per Capita and Country of Birth Relationships.' Journal of Business Ethics 116:655-66.

Meglino. B. M., E. C. Ravlin, and C. L. Adkins. 1989. 'A Work Values Approach to Corporate Culture.' Journal of Applied Psychology 74 (3): 424-32.

Meriac, J. P., D. J. Woehr, and C. Banister. 2010. 'Generational Differences in Work Ethic: An Examination of Measurement Equivalence Across Three Cohorts.' Journal of Business Psychology 25:315-24.

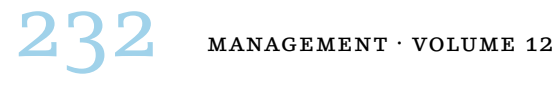


Miller, M. J., D. J. Woehr, and N. Hudspeth. 2002. 'The Meaning and Measurement of Work Ethic: Construction and Initial Validation of a Multidimensional Inventory.' Journal of Vocational Behaviour 60 (3): 451-89.

Mirels, H. L., and J. B. Garrett. 1971. 'The Protestant Ethic As a Personality Variable.' Journal of Consulting and Clinical Psychology 36:40-4.

Morrow, P. C., and J. F. Goetz. 1988. 'Professionalism As a Form of Work Commitment.' Journal of Vocational Behaviour 32:92-111.

Morrow, P. C., and J. C. McElory. 1987. 'Work Commitment and Job Satisfaction over Three Career Stages.' Journal of Organizational Behaviour 30:330-46.

Mulaik, S. A. 2010. Foundations of Factor Analysis. 2nd ed. Boca Raton, FL: CRC Press.

Ozatalay, K. C., and H. E. Chanzanagh. 2013. 'Examining the Validity of Mwep Scale in Turkish Culture.' Procedia: Social and Behavioural Sciences 82:220-25.

Petty, G. C., and R. B. Hill. 2005. 'Work Ethic Characteristics: Perceived Work Ethics of Supervisors and Workers.' Journal of Industrial Teacher Education 42 (2): 5-20.

Randall, D. M., and J. A. Cote. 1991. 'Interrelationships of Work Commitment Constructs.' Work and Occupation 18:194-211.

Ray, J. J. 1982. 'The Protestant Ethic in Australia.' Journal of Social Psychology 116:127-38.

Saks, A. M., P. E. Mudrack, and B. E. Ashforth. 1996. 'The Relationship between the Work Ethic, Job Attitudes, Intentions to Quit, and Turnover for Temporary Service Employees.' Canadian Journal of Administrative Sciences 13 (3): 226-36.

Saunders, M., P. Lewis, and A. Thornhill. 2009. Research Methods for Business Students. 5th ed. Upper Saddle River, NY: Pearson.

Shimko, B. W. 1992. 'Pre-Hire Assessment of the New York Force: Finding Wheat (and work Ethic) among the Chaff.' Business Horizons 35 (5): $60-6$.

Slabbert, A., and W. I. Ukpere. 2011. 'A Comparative Analysis of the Chinese and South African Work Ethic.' International Journal of Social Economics 38 (8): 734-41.

Stone. E. F. 1975. 'Job Scope, Job Satisfaction, and the Protestant Ethic: A Study of Enlisted Men in the us Navy.' Journal of Vocational Behaviour 7:215-24.

Tabachnick, B. G., and L. S. Fidell. 2007. Using Multivariate Statistics. Upper Saddle River, NY: Pearson.

Tang, T. L. P. 1993. 'A Factor Analytic Study of the Protestant Work Ethic.' The Journal of Social Psychology 133:109-11.

Weber, M. 1958. The Protestant Ethic and the Spirit of Capitalism. New York: Scribner. 
Woehr, D. J, L. M. Arciniega, and D. H. Lim. 2007. 'Multidimensional Work Ethic Profile, across Three Diverse Cultures.' Educational and Psychological Measurement 67: 154-68.

Wollack, S., J. G. Goodale, J. P. Wijting, and P. C. Smith. 1971. 'Development of the Survey of Work Values.' Journal of Applied Psychology 55:331-8.

Yandle, B. 1992. 'Does Anyone Still Care?' SuperVision 53 (9): 14-6.

This paper is published under the terms of the Attribution-

NonCommercial-NoDerivatives 4.0 International (CC BY-NC-ND 4.0)

License (http://creativecommons.org/licenses/by-nc-nd/4.o/). 